\title{
BMJ Open A multinational cross-sectional survey of the management of patient medication adherence by European healthcare professionals
}

\author{
Wendy Clyne, ${ }^{1}$ Comfort Mshelia, ${ }^{2}$ Sarah McLachlan, ${ }^{3}$ Peter Jones, ${ }^{4}$ \\ Sabina de Geest, ${ }^{5,6}$ Todd Ruppar, ${ }^{7}$ Kaat Siebens, ${ }^{6}$ Fabienne Dobbels, ${ }^{6}$ \\ Przemyslaw Kardas ${ }^{8}$
}

To cite: Clyne W, Mshelia C, McLachlan S, et al. A multinational cross-sectional survey of the management of patient medication adherence by European healthcare professionals. BMJ Open 2016;6:e009610. doi:10.1136/bmjopen-2015009610

- Prepublication history and additional material is available. To view please visit the journal (http://dx.doi.org/ 10.1136/bmjopen-2015009610).

Received 8 September 2015 Revised 2 December 2015 Accepted 7 December 2015

CrossMark

For numbered affiliations see end of article.

Correspondence to Dr Wendy Clyne;

wendy.clyne@coventry.ac.uk

\section{ABSTRACT}

Objectives: To examine which interventions healthcare professionals use to support patients with taking medicines and their perceptions about the effectiveness of those actions.

Design: Cross-sectional multinational study. Setting: Online survey in Austria, Belgium, England, France, Germany, Hungary, The Netherlands, Poland, Portugal and Switzerland.

Participants: A total of 3196 healthcare professionals comprising doctors (855), nurses (1047) and pharmacists (1294) currently registered and practising in primary care and community settings.

Main outcome measures: Primary outcome: Responses to the question 'I ask patients if they have missed any doses of their medication' for each profession and in each country.

Secondary outcome: Responses to 50 items concerning healthcare professional behaviour to support patients with medication-taking for each profession and in each country.

Results: Approximately half of the healthcare professionals in the survey ask patients with long-term conditions whether they have missed any doses of their medication on a regular basis. Pharmacists persistently report that they intervene less than the other two professions to support patients with medicines. No country effects were found for the primary outcome.

Conclusions: Healthcare professionals in Europe are limited in the extent to which they intervene to assist patients having long-term conditions with medication adherence. This represents a missed opportunity to support people with prescribed treatment. These conclusions are based on the largest international survey to date of healthcare professionals' management of medication adherence.

\section{INTRODUCTION}

The majority of research on medication adherence has focused on understanding
Strengths and limitations of this study

- This study is novel, with a large, multinational European sample of three healthcare professions (doctors, nurses and pharmacists), and is the largest survey to date of the behaviours undertaken in routine clinical practice in primary care to support patients in the use of their medicines.

- We provide evidence that there is scope for patients to be better supported with medicines use and the potential value of education and training for healthcare professionals to achieve this.

- There is a risk of self-selection bias and risks inherent in the self-reporting of behaviour.

and changing the patient, particularly their beliefs about medicines, ${ }^{1}{ }^{2}$ rather than understanding and changing the context in which care and treatment is provided. Systematic reviews show that interventionsdesigned to improve adherence for chronic health problems-such as patient education, psychological therapy, simplified dosing and family intervention, tend to be complex in nature and low in effectiveness. ${ }^{3}$

Some research has examined the role of healthcare professionals in patients' adherence, although this has focused predominantly on physicians' communication and characteristics. ${ }^{4}{ }^{5}$ Despite evidence from this research suggesting that healthcare professionals can significantly affect patients' adherence to medication, the beliefs, perceptions and practices of healthcare professionals have received relatively little attention. The effectiveness of adherence-enhancing interventions needs to be examined in a broader context that encompasses the role of healthcare professionals. Healthcare professionals have an 
important role to play in providing support to patients in order to ensure that if patients agree to take medicines, they do so in a safe, effective and cost-effective way. However, evidence suggests that healthcare professionals may not be fulfilling this role, in part as they tend to underestimate the incidence of nonadherence in their patients. ${ }^{6}$ Few physicians receive formal training in patient adherence, though the assessment of patient adherence and the use of adherence-enhancing interventions is significantly greater among those who do receive formal training. ${ }^{7}$ Improving the skills of healthcare professionals in properly assessing the risk of non-adherence in patients and delivering interventions aimed at reducing non-adherence, may therefore lead to more effective support for patients taking prescribed medicines.

In order to gain a more complete understanding of the range of potentially adherence-enhancing interventions delivered by healthcare professionals in routine daily practice and their perceived effectiveness, we conducted a survey on the adherence management of doctors, nurses and pharmacists across 10 European countries.

\section{METHODS}

\section{Design}

The paper focuses on the self-reported behaviours of primary care healthcare professionals in 10 European countries to support patients with taking prescribed medicines for long-term conditions, using a crosssectional online survey. The protocol for this study has been published elsewhere. ${ }^{8}$

\section{Setting and participants}

Participants were healthcare professionals who were currently registered to practice and employed as medical doctors, nurses or pharmacists, working with adults in primary or community care in 1 of 10 European countries: Austria, Belgium, England, France, Germany, Hungary, The Netherlands, Poland, Portugal and Switzerland.

Sample size was based on the estimation of the proportion of those participants who answer 'never' to the primary outcome: 'I ask patients if they have missed any doses of their medication' in each country. Following Cochran, ${ }^{9}$ a sample size of 384 health care professionals in each country (128 people for each professional group) was required to enable estimation with $95 \%$ confidence.

\section{Procedure}

A mixed-method approach was used to recruit participants in each country, adapted as necessary dependent on the availability and accessibility of national registers of healthcare professionals. Recruitment was via professional bodies and associations when registers were not available.
The online questionnaire was administered using SurveyMonkey.com (http://www.SurveyMonkey.com). No personal information (such as names, addresses and professional licence numbers) were collected from participants and no IP addresses were stored or downloaded. Ethics approval was provided by the NRES Committee North West Liverpool East (REC Reference 11/NW/ 0156) for England and used as the basis for ethics and research governance in the other European countries, adapted as necessary to meet national ethical requirements.

\section{Measures}

It was not possible to identify any validated scales of healthcare professional behaviour in this domain, but two unvalidated, published questionnaires have been used to measure adherence intervention behaviours and their perceived effectiveness among hospital-based doctors, ${ }^{4}$ and cardiovascular and transplantation nurses. ${ }^{10}$ Our questionnaire was informed by these previous studies, recommendations for clinical practice from published adherence guidelines, ${ }^{1}{ }^{10-12}$ and was discussed, reviewed and piloted by the research team. The questionnaire is available from the corresponding author.

Fifty questions concerning adherence-enhancing interventions were presented in five subsections: assessment of adherence and its risk factors (example item, 'I use electronic monitoring devices to assess patients' level of adherence'); providing information for carers and patients (eg, 'I check that patients understand the information that I have given them'); talking with patients about their medications (eg, 'I ask patients what level of involvement they would like in making decisions about their treatment'); practical strategies to make medication taking easier (eg, 'I help patients to tailor their medication regimen to their own lifestyle'); and involving others and services to support adherence (eg, 'I refer patients to peer mentor programmes to support medication adherence'). Following Berben et al, ${ }^{13}$ respondents were asked how often they used each intervention (from 'never' to 'all the time' with the response category 'not applicable' available to participants who did not use the intervention mentioned) and how effective they think that intervention is ('not at all' 'somewhat', 'extremely', with the option of responding 'don't know').

The survey was translated into the appropriate languages using accredited translators who were native speakers of the target languages and fluent in English. Translations were checked for compatibility with the original version in a process of back translation, performed by persons who were native English speakers and fluent in each target language. For each language, a third individual acted as a reviewer, and highlighted any discrepancies between the forward and back translations, which were resolved by discussion with the translators. Translations were coordinated by one project partner to 
ensure consistency. Piloting in each country enabled identification of any semantic inconsistencies.

\section{Primary and secondary outcomes}

The primary outcome was responses to the question 'I ask patients if they have missed any doses of their medication' for each profession and in each country.

Secondary outcomes were responses to the 50 items concerning healthcare professional behaviour to support patients with medication-taking for each profession and in each country.

\section{Statistical analysis}

Quantitative analyses for the primary outcome were performed using MLwiN (http://www.cmm.bristol.ac.uk/ MLwiN/) for both, binary and ordered categories. Responses to the primary outcome were categorised to form a binary variable coded as 1 if the intervention had never been used and 0 for all other response options. Participants who indicated that the item was not applicable to their particular role were excluded from the analysis. Post hoc we found that the frequency of the primary outcome (never asking patients if they had missed any doses of their medication) produced a relatively small number of responses; consequently, a further analysis was carried out using the binary outcome where patients were asked frequently or all the time about missed doses.

\section{Analysis of primary outcome}

We evaluated the effect on the primary outcome of groups of predictor variables. The group of demographic variables comprised gender and age of respondents, while professional practice encompassed number of years registered as a qualified healthcare professional, the average amount of time spent talking with patients about their use of medications, any pre-registration or post-registration training in medication adherence management and support, and the use of practitioner guidelines to assist with the management of patients' adherence. Multiple logistic regression was used, taking into account the hierarchical nature of the data, and the results are presented as ORs and their 95\% CIs. Where there were ordinal responses, the lowest was taken as the comparator value and ORs are presented for the binary responses for categorical variables, for instance the use of practitioner guidelines to assist with the management of patient adherence. Where there are variables measured over a more extensive range, such as age, then ORs represent the change per unit (per year for age). Where there appeared to be a trend in the predictors, this was tested. Logistic regressions were applied with random intercepts, which were allowed to vary at both the country and profession level, and fixed effects for all variables within the three groups. A preliminary analysis where the intercept was allowed to vary at the country level and with a profession fixed effect is also given. In practice, in most cases the country effects were not significant and models were refitted with only profession random effects.

\section{Structure of analysis}

Two sets of between-participants analysis of variance (ANOVA) were conducted on the data on healthcare professionals' use of adherence-enhancing interventions. First, a series of ANOVAs are reported for the main effects of profession and nation on healthcare professionals' total ratings for each of the five categories of adherence-enhancing interventions and perceived barriers to implementing interventions for adherence. Data for all professions and all participating nations were included in these analyses. To enable testing for potential interactions between profession and nation for each of the outcome variables, a second series of ANOVAs is reported. As data were not collected from nurses in France and Germany, the data from these nations were excluded in this second series of analyses. The sample sizes for both sets of analysis were considered large enough so that normality based tests were appropriate, however, inferences were checked using the nonparametric Kruskall-Wallis test.

\section{ANOVA: main effects}

All analyses were carried out using NCSS 2007 (V.07.1.19, J Hintze (2009), Kaysville, Utah, USA). Initially, a series of $3 \times 10$ between-participants ANOVAs using the General Linear Model (GLM) procedures was conducted to examine the main effects of profession and nation on total scores for healthcare professionals' use of adherence-enhancing interventions for each category of intervention. Corrections for multiple testing were carried out within each variable.

\section{ANOVA: interaction effects}

As data were not collected from nurses in France or Germany, a further series of ANOVAs was necessary to explore the effects of interactions between profession and nation on total ratings for healthcare professionals' use of adherence-enhancing interventions.

\section{RESULTS}

A total of 4967 healthcare professionals started the survey; 3196 reported their profession and were included in the analysis. Demographic information for the sample is presented in table 1. Means and SDs for specific adherence-enhancing interventions by profession and by nation can be found in online supplementary tables $1-4$.

\section{Primary outcome}

For both versions of the primary outcome, the ORs and their CIs suggest that pharmacists are approximately 2.8 times more likely than doctors to have a never response to the question 'I ask patients if they have missed any doses of their medication', and the doctors and nurses 


\begin{tabular}{|c|c|c|c|c|c|c|c|c|}
\hline Sample size & \multicolumn{8}{|c|}{$\begin{array}{l}\text { Total N=3196; Austria=698; Belgium=289; England=318; France=133; Germany=303; Hungary=322; The } \\
\text { Netherlands=91; Poland=571; Portugal=53; Switzerland=418; doctors=855; pharmacists=1294; nurses=1047 }\end{array}$} \\
\hline Age (mean and SD) & \multicolumn{8}{|c|}{$44.77(10.96)$} \\
\hline Gender & \multicolumn{8}{|c|}{ Male=1102; female=2069 } \\
\hline $\begin{array}{l}\text { Years since qualifying (frequency } \\
\text { distribution) }\end{array}$ & $\begin{array}{l}\text { Less than } \\
1 \text { year } \\
\mathrm{N}=86\end{array}$ & $\begin{array}{l}1-5 \text { years } \\
\mathrm{N}=354\end{array}$ & $\begin{array}{l}6-10 \text { years } \\
\mathrm{N}=374\end{array}$ & $\begin{array}{l}11- \\
15 \text { years } \\
N=439\end{array}$ & $\begin{array}{l}\text { Over } 15 \text { years } \\
\mathrm{N}=1935\end{array}$ & & & \\
\hline $\begin{array}{l}\text { Type of healthcare setting (frequency } \\
\text { distribution) }\end{array}$ & $\begin{array}{l}\text { Community } \\
\text { hospital } \\
\mathrm{N}=385\end{array}$ & $\begin{array}{l}\text { Family } \\
\text { medication/ } \\
\text { general practice } \\
\mathrm{N}=820\end{array}$ & $\begin{array}{l}\text { Specialist } \\
\text { community } \\
\text { service } \\
\mathrm{N}=104\end{array}$ & $\begin{array}{l}\text { Care/ } \\
\text { nursing } \\
\text { home } \\
N=155\end{array}$ & $\begin{array}{l}\text { Community } \\
\text { pharmacy/ } \\
\text { dispensary } \\
\mathrm{N}=1175\end{array}$ & $\begin{array}{l}\text { Community } \\
\text { nursing team } \\
\mathrm{N}=154\end{array}$ & $\begin{array}{l}\text { Polyclinic } \\
\mathrm{N}=45\end{array}$ & $\begin{array}{l}\text { Other } \\
\mathrm{N}=308\end{array}$ \\
\hline $\begin{array}{l}\text { Type of healthcare organisation (frequency } \\
\text { distribution) }\end{array}$ & $\begin{array}{l}\text { Privately } \\
\text { funded } \\
N=1127\end{array}$ & $\begin{array}{l}\text { State funded } \\
\mathrm{N}=1050\end{array}$ & $\begin{array}{l}\text { Insurance/sick } \\
\text { fund funded } \\
\mathrm{N}=531\end{array}$ & $\begin{array}{l}\text { Mixed } \\
\text { funded } \\
\mathrm{N}=44\end{array}$ & $\begin{array}{l}\text { Other funding } \\
\mathrm{N}=302\end{array}$ & & & \\
\hline $\begin{array}{l}\text { Length of time spent talking to patients } \\
\text { about their use of medications (frequency } \\
\text { distribution) }\end{array}$ & $\begin{array}{l}\text { No time at all } \\
\mathrm{N}=34\end{array}$ & $\begin{array}{l}\text { Less than } 1 \mathrm{~min} \\
\mathrm{~N}=158\end{array}$ & $\begin{array}{l}1-5 \min \\
\mathrm{N}=1715\end{array}$ & $\begin{array}{l}6-10 \min \\
\mathrm{N}=801\end{array}$ & $\begin{array}{l}11-15 \min \\
\mathrm{N}=226\end{array}$ & $\begin{array}{l}\text { More than } \\
15 \text { min } \\
N=199\end{array}$ & & \\
\hline Pre-registration training in medication & Yes & No & & & & & & \\
\hline $\begin{array}{l}\text { adherence management and support } \\
\text { (frequency distribution) }\end{array}$ & $\mathrm{N}=296$ & $\mathrm{~N}=1780$ & & & & & & \\
\hline Post-registration training in medication & Yes & No & & & & & & \\
\hline $\begin{array}{l}\text { adherence management and support } \\
\text { (frequency distribution) }\end{array}$ & $\mathrm{N}=684$ & $\mathrm{~N}=1392$ & & & & & & \\
\hline Any training in medication adherence & Yes & No & & & & & & \\
\hline $\begin{array}{l}\text { management and support (frequency } \\
\text { distribution) }\end{array}$ & $\mathrm{N}=803$ & $\mathrm{~N}=1268$ & & & & & & \\
\hline Use of practitioner guidelines to assist with & Yes & No & & & & & & \\
\hline $\begin{array}{l}\text { management of patient adherence to } \\
\text { medication (frequency distribution) }\end{array}$ & $\mathrm{N}=468$ & $\mathrm{~N}=1586$ & & & & & & \\
\hline
\end{tabular}


Table 2 Summary of multiple logistic regression for never asking patients about missed doses as the dependent variable

\begin{tabular}{|c|c|c|}
\hline Variable & OR & $95 \% \mathrm{Cl}$ \\
\hline \multicolumn{3}{|l|}{ Profession* } \\
\hline Doctor & 1.00 & \\
\hline Pharmacist & 2.80 & 1.71 to 4.58 \\
\hline Nurse & 0.92 & 0.50 to 1.69 \\
\hline \multicolumn{3}{|l|}{ Demographicsł } \\
\hline \multicolumn{3}{|l|}{ Gender } \\
\hline Male & 1.00 & \\
\hline Female & 0.91 & 0.59 to 1.43 \\
\hline \multicolumn{3}{|l|}{ Age } \\
\hline Per year & 1.02 & 0.84 to 1.24 \\
\hline \multicolumn{3}{|c|}{ Professional practice $\ddagger$} \\
\hline \multicolumn{3}{|c|}{$\begin{array}{l}\text { Number of years registered as a qualified healthcare } \\
\text { professional }\end{array}$} \\
\hline Less than 1 year & 1.00 & \\
\hline $1-5$ years & 0.22 & 0.07 to 0.71 \\
\hline $6-10$ years & 0.40 & 0.14 to 1.17 \\
\hline $11-15$ years & 0.31 & 0.10 to 0.92 \\
\hline Over 15 years & 0.22 & 0.08 to 0.60 \\
\hline
\end{tabular}

Time spent talking with patients about their use of medications

$\begin{array}{lll}\text { No time at all } & 1.00 & \\ \text { Less than } 1 \mathrm{~min} & 0.63 & 0.13 \text { to } 3.19 \\ 1-5 \mathrm{~min} & 0.18 & 0.04 \text { to } 0.84 \\ 6-10 \mathrm{~min} & 0.05 & 0.01 \text { to } 0.27 \\ 11-15 \mathrm{~min} & 0.08 & 0.01 \text { to } 0.57 \\ \text { More than } 15 \mathrm{~min} & 0.11 & 0.02 \text { to } 0.71\end{array}$

Pre-registration and/or post-registration training in

adherence management and support

$\begin{array}{ll}\text { No } & 1.00 \\ \text { Yes } & 0.59\end{array}$

0.59

0.33 to 1.06

Use of practitioner guidelines to assist with management of patient adherence to medication

$\begin{array}{ll}\text { No } & 1.00 \\ \text { Yes } & 0.82\end{array}$

0.42 to 1.58

${ }^{*}$ Intercept allowed to vary by country.

†Intercept allowed to vary by profession.

were not significantly different from each other. Pharmacists are also approximately 4.6 times less likely to ask patients frequently or all the time if they have missed any doses of their medication. The results for both outcomes are presented in tables 2 and 3 .

The country random effect was found to be nonsignificant. Both age and gender were found to have non-significant effects with ORs near 1 and 95\% CIs containing 1. Length of time registered as a qualified healthcare professional appears to have a positive effect on both outcomes. This is more marked for the never asked outcome; however, there is no discernible trend over the categories. For length of time spent talking with patients about their use of medications, there is a significant trend downwards $(\mathrm{OR}=0.524$ per unit change, $95 \%$ CI 0.36 to 0.727$)$ and upwards $(\mathrm{OR}=1.42 /$ unit change, $95 \%$ CI 1.27 to 1.57 ). Training, which was a binary variable reflecting any pre-registration and/or post-
Table 3 Summary of multiple logistic regression for asking patients about missed doses frequently or all the time as the dependent variable

\begin{tabular}{|c|c|c|}
\hline Variable & OR & $95 \% \mathrm{Cl}$ \\
\hline \multicolumn{3}{|l|}{ Profession* } \\
\hline Doctor & 1.00 & \\
\hline Pharmacist & 0.22 & 0.17 to 0.27 \\
\hline Nurse & 1.12 & 0.90 to 1.41 \\
\hline \multicolumn{3}{|l|}{ Demographics $†$} \\
\hline \multicolumn{3}{|l|}{ Gender } \\
\hline Male & 1.00 & \\
\hline Female & 1.02 & 0.84 to 1.23 \\
\hline \multicolumn{3}{|l|}{ Age } \\
\hline Per year & 1.01 & 1.00 to 1.01 \\
\hline \multicolumn{3}{|c|}{ Professional practice† } \\
\hline \multicolumn{3}{|c|}{$\begin{array}{l}\text { Number of years registered as a qualified healthcare } \\
\text { professional }\end{array}$} \\
\hline Less than 1 year & 1.00 & \\
\hline $1-5$ years & 2.19 & 1.09 to 4.38 \\
\hline $6-10$ years & 2.32 & 1.16 to 4.63 \\
\hline $11-15$ years & 1.90 & 0.96 to 3.77 \\
\hline Over 15 years & 2.08 & 1.08 to 4.00 \\
\hline
\end{tabular}

Time spent talking with patients about their use of medications

$\begin{array}{lll}\text { No time at all } & 1.00 & \\ \text { Less than } 1 \mathrm{~min} & 3.69 & 0.72 \text { to } 18.95 \\ 1-5 \mathrm{~min} & 3.88 & 0.80 \text { to } 18.89 \\ 6-10 \mathrm{~min} & 6.12 & 1.25 \text { to } 29.95 \\ 11-15 \mathrm{~min} & 8.40 & 1.67 \text { to } 42.31 \\ \text { More than } 15 \mathrm{~min} & 9.10 & 1.80 \text { to } 46.01\end{array}$

Pre-registration and/or post-registration training in

adherence management and support

$\begin{array}{lll}\text { No } & 1.00 & \\ \text { Yes } & 1.42 & 1.16 \text { to } 1.74\end{array}$

Use of practitioner guidelines to assist with management of patient adherence to medication

\begin{tabular}{lll} 
No & 1.00 & \\
Yes & 1.21 & 0.96 to 1.52 \\
\hline
\end{tabular}

*Intercept allowed to vary by country.

†Intercept allowed to vary by profession.

registration training in medication adherence management and support, has a nearly significant effect for the never category, where those who reported training were approximately $60 \%$ less likely to never ask patients about missed doses. For the frequently/always outcome, training predicts an approximately $42 \%$ increase in this outcome. The use of practitioner guidelines to assist with the management of patient adherence to medication does not reach significance but point estimates of the ORs indicate similar positive effects for both outcomes.

\section{Internal reliability of measures}

Cronbach's $\alpha$ indicated that the items assessing 'providing information for patients/carers' $(\alpha=0.80)$, 'talking with patients about their medications' $(\alpha=0.87)$, 'practical strategies to make medication taking easier' $(\alpha=0.83)$, and involving others and other services to 
support adherence' $(\alpha=0.72)$ showed good internal reliability. The internal reliability of the measure for 'assessment of adherence and its risk factors' fell marginally below the accepted level of $0.70 \quad(\alpha=0.69)$. Results derived from the total ratings for this section should, therefore, be interpreted with caution.

Some categories of interventions were found to have a high correlation with each other, using Pearson's $r$ with a cut-off level of 0.5. Higher scores for frequency of use of assessment interventions were found to correlate with higher scores for the use of interventions focused on talking with patients about their medications $(\mathrm{r}=0.53)$. High scores for the use of interventions focused on talking with patients about their medications were also correlated with higher reported use of practical strategies to make medication taking easier $(\mathrm{r}=0.58)$.

\section{ANOVA: main effects}

For the assessment of adherence and its correlates, a significant main effect was obtained for profession, $\mathrm{F}$ (2, $1678)=129.48, \mathrm{p}<0.001$. A Bonferroni multiple comparison test at the $5 \%$ level of significance showed that all three professional groups were significantly different from each other. Nurses reported significantly greater use of these interventions than doctors and pharmacists. Doctors also reported significantly greater use of these interventions than pharmacists, $\mathrm{p}<0.05$. There was also a significant main effect of nation on reported use of interventions for the assessment of adherence and its risk factors, F $(9,1678)=4.99$, $\mathrm{p}<0.001$. England, Portugal and the Netherlands showed greater use of these interventions, and French healthcare professionals showed the lowest use of assessment interventions.

For interventions focused on providing information for patients or carers, there was a significant main effect of profession on healthcare professionals' reported use, $\mathrm{F}(2,1990)=62.36, \mathrm{p}<0.001$. A Bonferroni multiple comparison test indicated that doctors reported significantly more frequent use of these interventions than nurses or pharmacists, and nurses used these interventions significantly more often than pharmacists, $\mathrm{p}<0.05$. A significant main effect of nation was also determined, $F(9,1990)$ $=14.06, \mathrm{p}<0.001$. Again, healthcare professionals in England, the Netherlands and Portugal reported more frequent use of these interventions. Austrian healthcare professionals reported the lowest use of this category of intervention.

The ANOVA conducted on the total use of interventions regarding talking with patients about their medications revealed a significant main effect of profession, $\mathrm{F}$ $(2,547)=40.83, \mathrm{p}<0.001$. A Bonferroni multiple comparison test showed that nurses reported significantly more use of these interventions than doctors and pharmacists, and doctors reported significantly greater use than pharmacists, $\mathrm{p}<0.05$. There was also a significant main effect of nation, $F(5,547)=4.41, \mathrm{p}<0.001$. More use of these interventions was reported by healthcare professionals in
Portugal and the Netherlands, and the least use was reported by those in Belgium.

For healthcare professionals' reported use of practical strategies to make medication taking easier, a significant main effect of profession was determined, F (2, 1249) $=86.34, \mathrm{p}<0.001$. A Bonferroni multiple comparison test showed that doctors reported significantly greater use of these interventions than nurses and pharmacists, and nurses reported significantly more use than pharmacists, $\mathrm{p}<0.05$. A significant main effect of nation also emerged, $\mathrm{F}(8,1249)=7.19, \mathrm{p}<0.001$. Use of these interventions was highest in England, the Netherlands and Portugal and lowest in Austria and Switzerland.

For the final category of interventions, focused on involving others and other services to support adherence, a significant main effect of profession was found, $\mathrm{F}(2,1408)=63.85, \mathrm{p}<0.001$. A Bonferroni multiple comparison test revealed that nurses reported significantly greater use of these interventions than doctors and pharmacists, $p<0.05$. Further, the mean total reported use of these interventions by doctors was significantly higher than the mean total use by pharmacists, $\mathrm{p}<0.05$. A significant main effect of nation was also observed for this outcome, F $(9,1408)=26.55, p<0.001$. Healthcare professionals in Poland reported the highest use of these interventions, and those in Austria, Germany and Switzerland reported the least.

\section{ANOVA: interaction effects}

For the category of interventions pertaining to the assessment of adherence and its risk factors, a significant main effect of profession was determined, F (2, 1445) $=8.98, \mathrm{p}<0.01$. There was, however, no significant main effect of nation, $F(7,1445)=.62, p>0.05$. A significant interaction between profession and nation emerged, $\mathrm{F}$ $(14,1445)=7.73, \mathrm{p}<0.001$. Pharmacists in England, the Netherlands and Portugal reported more use of these interventions than pharmacists from other countries. Nurses in Austria and Switzerland reported less use of these interventions than nurses in other countries.

There were no significant main effects of profession, $\mathrm{F}$ $(2,1689)=1.35, \mathrm{p}>0.05$, or nation, $\mathrm{F}(7,1689)=1.30$, $\mathrm{p}>0.05$, on healthcare professionals' reported use of interventions centred on the provision of information for patients and carers. However, a significant profession $\mathrm{x}$ nation interaction was found, $\mathrm{F}(14,1689)=8.83$, $\mathrm{p}<0.001$. Nurses in England reported much higher, and nurses in Austria much lower, use of these interventions than nurses in other nations. Pharmacists in the Netherlands and Portugal reported more frequent use of these interventions, and pharmacists in Poland and Switzerland less frequent use of these interventions.

For the use of interventions focused on talking with patients about their medications, a significant main effect of profession was determined, $\mathrm{F}(2,471)=7.80$, $\mathrm{p}<0.05$. There was no significant main effect of nation, $F$ $(4,471)=2.03, p>0.05$. However, a significant profession $\mathrm{x}$ nation interaction effect was found, $\mathrm{F}(8,471)=2.52$, 
$\mathrm{p}<0.05$. Nurses in the Netherlands reported higher use of interventions in this category than nurses in other countries. Pharmacists in Belgium and Switzerland reported lower use of interventions in this category.

A similar pattern of findings was determined for healthcare professionals' use of practical strategies to make medication taking easier. A significant main effect of profession was found, $\mathrm{F}(2,1064)=10.50, \mathrm{p}<0.01$, but there was no significant main effect of nation, F (6, $1064)=1.42, p>0.05$. A significant interaction effect was found, F $(14,1064)=4.18, \mathrm{p}<0.001$. Doctors in England, the Netherlands and Switzerland reported lower use of these interventions than doctors in other nations. Nurses and pharmacists in England and the Netherlands had higher use of interventions in this category than nurses elsewhere.

For the final category of interventions, focused on involving others and other services to support adherence, significant main effects were found for profession, $\mathrm{F}(2,1201)=8.19, \mathrm{p}<0.01$, and for nation, $\mathrm{F}(7,1201)$ $=6.95, \mathrm{p}<0.01$. Nurses reported significantly greater use of these interventions than doctors and pharmacists, $\mathrm{p}<0.05$. Healthcare professionals in Portugal and Poland reported more frequent use of interventions than healthcare professionals in other nations. A significant profession $\mathrm{x}$ nation interaction effect was also shown, $\mathrm{F}$ $(14,1201)=3.44, \quad \mathrm{p}<0.001$. Pharmacists in Poland reported much lower use of these interventions than Polish doctors and nurses who completed the survey.

\section{DISCUSSION}

\section{Main findings}

Healthcare professionals in Europe are limited in the extent to which they intervene to assist patients having long-term conditions with medication adherence. Within intervention categories, mean total scores are around or below the mid-point for 'assessment of adherence', 'practical strategies to make medication taking easier' and 'involving others to support adherence'. The categories 'providing information for patients/carers' and 'talking with patients about their medications' (of which giving patients the opportunity to ask questions is highly rated) both score slightly above the mid-point of the total scale, suggesting these categories of intervention are practised somewhat more frequently.

The analysis of the primary outcome, and of the 'assessment of adherence' category as a whole, generates concern about the extent to which healthcare professionals seek to identify medication non-adherence in routine clinical practice. Participants in the survey were asked to answer each question only if the specific item was relevant to their role. Thus participants for whom the item was relevant to their role, and so answered the question, could potentially have asked all patients about missed doses of prescribed medication. In fact, about half of the healthcare professionals in the survey ask patients with long-term conditions whether they have missed any doses of their medication on a regular basis, a question identified as a key method for healthcare professionals to assess adherence and so support patients with medicines. ${ }^{12}$ However, the finding that healthcare professionals who report that they have had some element of training in medication adherence are more likely to ask this key question, indicates that healthcare professional behaviour may be amenable to change in this regard.

Consistent differences were found in the extent to which doctors, pharmacists and nurses report that they manage and support patients with medication adherence. For the primary outcome, and all five categories of adherence intervention, pharmacists persistently report that they intervene less than the other two professions to support patients with medicines. In three instances of five, nurses reported more intervention to assist patients with prescribed medicines than doctors.

The differences between professions in the extent to which they report that their day to day practice includes supporting patients with long term conditions with medicines use is cause for concern. Within the primary care team, pharmacists have particular expertise and training in pharmaceuticals, yet this does not appear to translate into a lead role in supporting patients with medicines use within routine practice. It is possible that the physical environment and role of many pharmacists in community and primary care settings may hinder their ability to assist patients to the same extent as nurses and doctors. However, in this survey, pharmacists report no less time spent talking with patients about their use of medications than doctors, though both groups report that they typically have less time than nurses do to spend with individual patients. It is also unlikely that access to training inhibited pharmacists from intervening to support patients with medication adherence: pharmacists in this study reported receiving more adherence training than either nurses or doctors. Future research might usefully consider whether aspects of service provision, type and nature of training or healthcare culture contribute to these differences in clinical behaviour.

No country effects were found for the primary outcome examining responses to the question specifically concerning whether healthcare professionals ask patients if they have missed any doses of their medication. Differences between countries were found in the extent to which healthcare professionals in primary care settings intervene to support patients with medicines use. Healthcare professionals in England, the Netherlands and Portugal report more activity to support patients with medicines use for three of the five categories of intervention ('assessment of adherence', 'providing information for patients/carers' and 'practical strategies to make medication taking easier') than healthcare professionals in the other countries. Healthcare professionals in the Netherlands and Portugal, but not England, also report more activity in the 'talking with patients about medications' category. 
The pattern of findings is different for the 'involving others and other services to support adherence' category, for which Polish healthcare professionals report more activity than healthcare professionals in other countries. Interaction effects between profession and countries are reported above for completeness but should be interpreted with caution in the absence of a main effect of country in the majority of these analyses.

The relatively small sample of healthcare professionals in Portugal cautions against over-interpretation of findings for this nation. Results from England, the Netherlands and Poland, however, are supported by much larger samples.

A clear theme regarding the use of adherence-enhancing interventions by healthcare professionals is the low reported use of technology and other resources to support patients with medicines use in routine practice. Resource-intensive approaches are utilised less than resource-light approaches. Thus, blood or urine screens and electronic monitoring to assess medication adherence, DVDs, video or computer resources for information provision, and reminder systems such as text messaging, mobile alarms, reminder charts and diaries, are used less to support medication adherence than nontechnological, simple approaches, such as information sharing and talking with patients about their medicines use. Unfortunately, from this survey, we are unable to determine whether this is due to the lack of availability of such resources or a preference by healthcare professionals for less technologically-driven approaches. However, we do know that healthcare professionals who report use of these resource-intensive interventions, and thus respond to the questions about perceived effectiveness of the intervention items, are in general more likely to report that they 'don't know' how effective the interventions are than participants responding to other items.

Healthcare professionals in the study reported that, of the interventions they use, provision of information to patients and talking with patients about their medicines use are more effective than other ways of intervening, in their view. However, the sample does not strongly endorse the effectiveness of many of the interventions they use; only 10 of the 50 interventions have a modal response of 'extremely' effective. It is possible then that healthcare professionals struggle to get feedback on the utility and effectiveness of their own actions towards supporting patients with medication adherence. If so, healthcare professionals may find it difficult to reflect on, learn from and adapt their own practice to support medicines use.

\section{Strengths and limitations}

In some countries, and for some professions, participant recruitment, did not reach the target sample size. Recruitment of general practitioners into the study was a particular problem for some countries. In England, for example, recruitment of pharmacists and nurses to the study was steady and straightforward. Professional bodies and regulators for general practitioners (GPs), however, were less able to assist with recruitment. Two countries, France and Germany, did not plan to collect data for nurses working in a primary care setting. Survey partners in those countries reported that the study topic was not so relevant to the role of nurses in those nations. For some analyses, the absence of a nurse sample for all countries meant that interaction effects could not be reported unless the whole data set for those specific countries was excluded.

The study focused on the behaviours of healthcare professionals working in a primary care setting. This study does not tell us about behaviours to support medication adherence by those working in secondary care health services, nor is it possible to determine the extent to which the results of the present study may be generalisable to other settings. The survey concerns self-report by healthcare professionals of the interventions they undertake towards managing and supporting patients with medication adherence. We have no objective evidence to support these self-reports. Equally, we have no information about the patient experience of support with medicines taking by the professionals participating in the study. Furthermore, healthcare professionals completing this survey chose whether to participate or not. This self-selected sample may be more interested in medicines and medicines use than the healthcare professional population at large. If so, this study may overestimate the proportion of healthcare professionals who use adherence-enhancing interventions.

To our knowledge, however, this study is the largest survey of European healthcare professionals' behaviour towards supporting patients with medication adherence. Keeping in mind the caveats above, the results add to our understanding of how frequently healthcare professionals intervene to support patients with medicines use in everyday practice, and their perceptions of the efficacy of that intervention. The international nature of this study enables analysis of variability observed in healthcare professionals' beliefs and behaviours across 10 European nations. This may provide a basis within each country for promoting routine and continuous efforts, to educate and modify the behaviour of healthcare professionals in order to enable them to fulfil their roles in supporting patients with medicine taking.

\section{Implications for clinicians and policymakers}

Our study shows that there is plenty of scope for primary care healthcare professionals to increase the frequency with which they provide support to patients with longterm conditions who are prescribed medication.

This study provides evidence to support a strong case for educators to reflect on the nature and extent of the education and training provided to healthcare professionals, for managing and supporting patients with medication adherence. Our educational framework, based in part on this survey, ${ }^{13}$ which includes a 
competency framework, learning outcomes and an assessment tool, may form a basis for education for preregistration training and for continuing professional development for healthcare professionals.

We recommend that a quality standard for medication adherence support for people with long-term conditions should be implemented in primary care settings in Europe, based on the following quality statement: people prescribed medication(s) for long-term conditions receive an assessment that identifies the extent of their non-adherence to medication. The recommended quality measure is the proportion of patients prescribed medication who are asked whether they have missed any doses of their medication for a recent timeframe during their most recent consultation (numerator-the number of people with a long-term condition prescribed medication who were asked whether they have missed any doses of their medication during their most recent consultation; denominator-the number of all patients with a long-term condition prescribed medication). The aim of this quality standard is to make medication adherence assessment a regular and routine part of primary healthcare, and so provide a basis for healthcare professionals to support patients reporting non-adherence with medicines use when necessary.

\section{Unanswered questions and future research}

Further study is needed to investigate ways in which healthcare professionals can receive feedback about the impact and effectiveness of specific adherenceenhancing interventions used in routine clinical practice, to support them in reflecting on and improving their practice. Previous studies of clinical behaviour change for other aspects of clinical practice have used social cognitive theory to understand the determinants of healthcare professional behaviour and as the basis for the design of interventions to change the clinical practice of healthcare professionals. ${ }^{14-16}$ Future research might adopt the same approach in the development of interventions improve the uptake of medication adherence guidelines by healthcare professionals.

We have also identified a discrepancy between the nature of medicines adherence support provided in routine clinical practice and the nature of the often complex adherence-enhancing interventions reported in intervention studies. ${ }^{3}$ The implementation of trial-based interventions into routine clinical practice is likely, therefore, to need careful consideration.

\section{CONCLUSION}

Healthcare professionals in Europe are limited in the extent to which they intervene to assist patients with long-term conditions with medication adherence. This represents a missed opportunity to support people with prescribed treatment.
Author affiliations

${ }^{1}$ Faculty of Health and Life Sciences, Coventry University, Coventry, UK

${ }^{2}$ Leeds Institute of Health Sciences, Leeds University, Leeds, UK

${ }^{3}$ King's College, London, UK

${ }^{4}$ Institute of Science and Technology in Medicine, Keele University, Keele, UK

${ }^{5}$ Institute of Nursing Science, University of Basel, Switzerland

${ }^{6}$ Academic Centre for Nursing and Midwifery, KU Leuven, Leuven, Belgium

${ }^{7}$ Sinclair School of Nursing, University of Missouri, Columbia, USA

${ }^{8}$ First Department of Family Medicine, Medical University of Lodz, Lodz, Poland

Acknowledgements The authors would like to thank Ms Stephanie Hall, School of Medicine and Dentistry, University of Aberdeen, for her contribution to the development of the healthcare professionals' survey and study protocol. The authors would also like to thank all survey partners for their assistance with data collection across Europe: Austria - Lorenz Auer-Hackenberg, Department of Medicine I, Division of Infectious Diseases and Tropical Medicine, Medical University of Vienna. Univ Lect Dr Heimo Lagler, Department of Medicine I, Division of Infectious Diseases and Tropical Medicine, Medical University of Vienna. Asst Prof Priv Doz Dr Michael Ramharter, Department of Medicine I, Division of Infectious Diseases and Tropical Medicine, Medical University of Vienna. Belgium—Professor Dr Veerle Foulon, Faculty of Pharmaceutical Sciences, KU Leuven. FranceFabrice Baton, Kappa Santé. Charlotte Drochon, Kappa Santé. Nathalie Texier, Kappa Santé. Dr Eric Van Ganse, University of Lyon. Germany—Sabine Breiholz, Drug Commission of German Pharmacists (AMK). Dr Med Lilian Krist, Institute for Social Medicine, Epidemiology and Health Economics, Charité University Medical Centre, Berlin. PD Dr Med Falk Müller-Riemenschneider, Institute for Social Medicine, Epidemiology and Health Economics, Charité University Medical Centre, Berlin. Hungary-Dr Balogh Zoltán, President, Hungarian Chamber of Health Professionals. Berend, Dóra, Health Marketing Research Centre, Marketing and Media Institute, Corvinus University, Budapest. Dr Horváth Tamás, President, Hungarian Chamber of Pharmacists. Dr Éger István, President, Hungarian Medical Chamber. Dr Simon Judit, Health Marketing Research Centre, Marketing and Media Institute, Corvinus University, Budapest. NetherlandsJan Hermsen, The Netherlands Institute for Health Services Research, Utrecht. Dr Liset van Dijk, The Netherlands Institute for Health Services Research, Utrecht. Portuga —Dr Luis Caldeira, National Authority of Medicines and Health Products (INFARMED), Lisbon. Frederico Saraiva, National Authority of Medicines and Health Products (INFARMED), Lisbon. Switzerland-Professor Dr Kurt E Hersberger, Department of Pharmaceutical Sciences, University of Basel. Dr Marie P Schneider, Department of Pharmacy, Policlinique Médicale Universitaire, Lausanne. Esther Spinatsch, Department of Pharmaceutical Sciences, University of Basel. PD Dr Andreas Zeller, Institute for General Internal Medicine, University of Basel.

Contributors WC was the principal investigator of the study. WC, CM, SM, SdG, TR, KS, FD and PK designed the study, PJ was responsible for data analysis and WC, PJ and SM for data interpretation. All the authors helped to draft the manuscript and approved the final version.

Funding This study, as part of the $\mathrm{ABC}$ project, was funded by the European Commission Seventh Framework programme (FP7 Theme Health, 2007-3.1-5, grant agreement number 223477). The final project report is available here: http://abcproject.eu/img/ABC\%20Final.pdf.

Competing interests None declared.

Ethics approval Ethics approval was provided by the NRES Committee North West-Liverpool East (REC Reference 11/NW/0156).

Provenance and peer review Not commissioned; externally peer reviewed.

Data sharing statement No additional data are available.

Open Access This is an Open Access article distributed in accordance with the Creative Commons Attribution Non Commercial (CC BY-NC 4.0) license, which permits others to distribute, remix, adapt, build upon this work noncommercially, and license their derivative works on different terms, provided the original work is properly cited and the use is non-commercial. See: http:// creativecommons.org/licenses/by-nc/4.0/ 


\section{REFERENCES}

1. Horne R, Weinman J. Self-regulation and self-management in asthma: exploring the role of illness perceptions and treatment beliefs in explaining non-adherence to preventer medication. Psychol Health 2002;17:17-32.

2. Horne R, Buick D, Fisher M, et al. Doubts about necessity and concerns about adverse effects: identifying the types of beliefs that are associated with non-adherence to HAART. Int J STD AIDS 2004;15:38-44.

3. Haynes RB, Ackloo E, Sahota N, et al. Interventions for enhancing medication adherence. Cochrane Database Syst Rev 2008;(2): CD000011.

4. DiMatteo MR, Sherbourne CD, Hays RD, et al. Physicians' characteristics influence patients' adherence to medical treatment: results from the medical outcomes study. Health Psychol 1993;12:93-102.

5. Zolnierek KB, DiMatteo MR. Physician communication and patient adherence to treatment: a meta-analysis. Med Care 2009;47: 826-34.

6. Macintyre CR, Goebel K, Brown GV. Patient knows best: blinded assessment of nonadherence with antituberculous therapy by physicians, nurses, and patients compared with urine drug levels. Prev Med 2005;40:41-5.

7. Patel UD, Davis MM. Physicians' attitudes and practices regarding adherence to medical regimens by patients with chronic illness. Clin Pediatr 2006;45:439-45.

8. Clyne W, Mshelia C, Hall S, et al. Management of patient adherence to medications: protocol for an online survey of doctors, pharmacists and nurses in Europe. BMJ Open 2011;1: e000355.

9. Cochran WG. Sampling techniques. 3rd edn. New York: Wiley, 1977.

10. Horne R, Weinman J, Barber N, et al. Concordance, adherence and compliance in medicine taking. National Co-ordinating Centre for NHS Service Delivery and Organisation R \& D, 2005.

11. Nunes V, Neilson J, O'Flynn N, et al. Clinical guidelines and evidence review for medicines adherence: involving patients in decisions about prescribed medicines and supporting adherence. London: National Collaborating Centre for Primary Care and Royal College of General Practitioners, 2009.

12. Sabaté E. Adherence to long-term therapies-evidence for action. Geneva: World Health Organisation, 2003.

13. Berben $\mathrm{L}$, Bogert $\mathrm{L}$, Leventhal ME, et al. Which interventions are used by health care professionals to enhance medication adherence in cardiovascular patients? A survey of current clinical practice. Eur $J$ Cardiovasc Nurs 2011;10:14-21.

14. http://publications.nice.org.uk/medicines-adherence-cg76/ guidance\#supporting-adherence (accessed 25 Mar 2015)

15. http://abcproject.eu/img/ABC\%20Project\%20Managing\%20and\% 20Supporting\%20Medication\%20Adherence.pdf and https://itunes. apple.com/gb/book/managing-supporting-medication/id543521021? $\mathrm{mt}=13$ (accessed 25 Mar 2015).

16. Godin G, Bélanger-Gravel A, Eccles M, et al. Healthcare professionals' intentions and behaviours: a systematic review of studies based on social cognitive theories. Implement Sci 2008;3:36. 